\title{
In Defense of the Printed Book
}

"But nowadays, instead of looking at books, people read them."

$\sim$ George Bernard Shaw

As a librarian, I am often asked about the imminent demise of the printed book. The question comes from all sorts: friends and family concerned about the viability of my chosen profession, bibliophiles worried about losing the books they love so much, and even the occasional stranger who wishes to provoke me into a passionate rant about the printed word. My answer, however, is always the same. Books will never go away. Though society will change and adapt to new technologies, the printed book will remain constant.

I'm not denying that digital texts offer many advantages. You can take thousands of digital texts on vacation without weighing down your suitcase. Electronic texts offer instant definitions or translations of words via dictionary software embedded in the reader. Digital texts often come with hyperlinks, videos, and websites embedded in the text. Plus, you don't have to kill trees to produce a digital text, making them far more sustainable than printed books. There is even a new app called Spritz for digital texts that makes speed reading easier; the programmers claim their product will enable readers to read a full novel in 90 minutes flat. ${ }^{1}$ The app creates a single focal point: the words move so that your eyes don't have to.

Conversely, the pages of a printed book are fixed. Turning pages forces readers to physically interact with a book. You feel the paper between your fingers, hear the page crinkle softly as it turns. Digital texts are malleable and movable: the reader can change the font size or the line spacing, which changes where the words fall on the screen and the division of pages. Readers anticipate turning pages so much that some digital readers mimic this action electronically. Internet Archive, a large online resource for digitized books, displays its books with a page-turning graphic and the sound of a turning page. Apple even patented its page-turning technology. ${ }^{2}$

Pages also act as a kind of literary fuel gauge, displaying the amount of text that has been read as well as the amount left to read. You might argue that a scroll bar

1. "Homepage" Spritz, available online at http://spritzinc.com/ [accessed 28 January 2016].

2. Nick Bilton, "Apple Now Owns the Page Turn," Bits, The New York Times, November 16, 2012, available online at http:/ / bits.blogs.nytimes.com/2012/11/16/apple-now-owns-the-pageturn/?smid=tw-nytimesbits [accessed 28 January 2016]. 
does the same thing by noting the percentage of text that's been read. But if you've ever been so caught up in a good story that you're surprised when you notice how the fingers of your right hand barely hold any pages, you know what I'm talking about. There's absolutely no substitute for that feeling.

A friend of mine once put a name to this phenomenon. He called it "the pinch": that point where there are so few pages left to read that your fingers seem to touch through them. It's the point when you realize you've nearly reached the end. Do you read faster to find out what happens? Do you savor each word to make the story last longer? Regardless, the pinch becomes the physical manifestation of the emotion a reader experiences near the end of a good book. It embodies simultaneous anticipation and dread: anticipation of finding out what happens, dread that the book will end.

Printed books allow you to use a fixed text as a spatial representation of the information. The "method of loci," employed by the Ancient Greeks and Romans to aid memory, refers to the creation of a physical space (or "memory palace") in your mind where you keep information. ${ }^{3}$ By storing information in a particular location, you can more easily recall it. The Book of Kells, for example, contains architectural borders to frame the page along with detailed illumination to differentiate the pages from each other. The columns and arches aid in creating a memory palace by giving structure to the page. The scrollwork, Celtic knots, and mythic figures give the reader something on which they can meditate, while also adding uniqueness. The distinctiveness of the page allows a reader to say, "I think the text I'm looking for was on a page with a dragon."

While the formal "method of loci" is rarely used anymore, readers unconsciously use geographic searching to remember information every day. By visualizing the location or the physical appearance of the information, you might remember the information you needed was on the right-hand page, near the top, in a shorter paragraph. Or it was in the second half of the book, on the left, as the last sentence before a chapter break. This might help you remember either what was read or make it easier to find the information again.

One of the main advantages of digital texts is the ability to keyword search. However, this can become frustrating if you need an idea or concept versus a specific term or phrase. Often it is easier to relocate information using spatial memory through the printed book. When looking for information that cannot be found using a search term, the ability to flip through pages and sections quickens the search.

3. Nigel J.T. Thomas, "Ancient Imagery Mnemonics" (Berkeley, Calif.: Stanford University, 2014), available online at http://plato.stanford.edu/entries/mental-imagery/ancient-imagery-mnemonics. html [accessed 28 January 2016]. 
Physical pages allow you to flip back and forth between sections more easily than a digital text. Many e-readers turn one page at a time or require you to enter a specific location. You must know exactly where in the text the information can be found, either as a location identifier or percentage. What if, while reading A Game of Thrones, you need to consult the map to know how close Daenerys Targaryen is to King's Landing? The printed book allows you to put your finger in the page you're reading while flipping to the endpapers where the map is printed.

Printed pages allow you to flip back and forth quickly, but they also allow you to leave your mark on the book. Each interaction with a printed book leaves behind clues about the people who read it. My favorite text is The Book Thief. I have read it several times. The first time, I borrowed it from the library, but the story was so engaging I had to own the book. I even bought and read the Kindle version when I forgot the paperback at my dad's house.

Although the text doesn't change from version to version, my favorite is my paperback copy. My brother borrowed it and took it to the pool, where he accidentally set it down in a puddle. I still tell him that he owes me a new hardcover version, but secretly I prefer my paperback's softly rippled pages. It has a crease in its spine where I flattened it against the table so I wouldn't have to stop reading to eat. The cover is slightly faded from when I spent a week reading it at the beach. It has an infuriating dog-eared page from a friend who didn't have a bookmark. The cover has frayed edges from spending so many days in my purse. Each imperfection sparks a memory of reading or sharing it with someone I love.

Clearly, I am passionate about books. The printed book doesn't need to be charged, and you'll never have to upgrade its software. You can't break the screen and it will never try to sell you something or distract you with videos. However, as a librarian, I will never argue that people should read only printed books. Rather, I argue that people should read everything: books, magazines, newspapers, websites, e-books, ads, billboards. Everything. Reading is essential to learning and expanding our viewpoints, and we should all read however and whenever we can, using whatever method we prefer.

But when you go home tonight, go to your bookshelf and pick up your favorite book. Let it fall open to your favorite passage and appreciate the way it speaks to you as you run your fingers over the textured page. Clutch it to your chest and let the memories pass over you. Read your old notes and squeeze new ones in the remaining margin.

Experience the book. 